\title{
Physiological Phimosis and The Use of Topical Steroid
}

\section{David Shrestha ${ }^{1}$, Anup Shrestha ${ }^{2}$}

${ }^{1}$ Department of Surgery, Western Regional Hospital, Pokhara Academy of Health Sciences, Pokhara, Nepal ${ }^{2}$ Department of Surgery, Kaski Model Hospital, Pokhara, Nepal

\section{Correspondance:}

Dr. David Shrestha, MS

Department of Surgery, Pokhara Academy of Health Sciences

Western Regional Hospital, Pokhara

Email: pokhrelidavid@yahoo.com

Article received: Jan 302020

Article accepted: June 72020

\section{ABSTRACT}

Background : Aim of this study is to see the efficiency of topical $1 \%$ hydrocortisone in the treatment of physiological phimosis.

Materials and Methods: Retrospective study was conducted in the Kaski Model Hospital, Pokhara, Gandaki, Nepal from January 2016 to June 2019. Forty-nine patients treated in outpatient basis have been selected for this study. Selection was made according to Kikiros and Woodward retractability grading.

Results: Out of 49(100\%) patients 40(81.63\%) achieved complete response to steroid, which is Kikiros and Woodward retractability grade $0.2(4.08 \%)$ patients showed satisfactory response (symptom free) which is Kikiros and Woodward retractability grade 1 . And $7(14.28 \%)$ patients showed no response after six weeks course of treatment and underwent circumcision.

Conclusion: This study demonstrates the use of $1 \%$ topical hydrocortisone is safe, simple and cost effective. And it could be the initial choice of treatment.

KeyWords: Physiological phimosis, Topical 1\% hydrocortisone, Kikiros and Woodward retractability grading

\section{Introduction}

Phimosis is known as tight preputial ring distally which makes retraction of prepuce difficult or impossible to expose the glans. To avoid unnecessary procedure physiological and pathological phimosis should be differentiated prior to treatment. During birth about $96 \%$ of male child have non-retractile foreskin. ${ }^{1}$ It is mostly physiological in new born and younger children because of adhesion of glans and prepuce. ${ }^{1}$ Diagnosis of physiological phimosis is made when distal portion of foreskin is healthy and pouts with gentle retraction.
Whereas pathological phimosis affects about $6 \%$ of child with peak incidence at eleven years of age. ${ }^{2}$ The diagnosis is made with the gentle traction that leads to formation of cone-shaped structure with the distal narrow part being white and fibrotic. The choice of treatment for the physiological phimosis is controversial. In the past circumcision has become the popular approach. Gradually stretching of foreskin has been widely used and recently topical steroid have gain popularity due to its good success rate, about $65 \%-90 \%{ }^{3}$ cost effective and free of surgical and anesthetic complication. 
Original Article

Materials and Methodology

The retrospective study was conducted in the Kaski Model Hospital, Pokhara, Gandaki, Nepal from January 2016 to June 2019. Verbal and written consent was obtained. Forty-nine patients who were treated in outpatient basis have been selected for this study. Selection was made according to Kikiros and Woodward retractability grading. The parents were taught to apply $1.0 \%$ Hydrocortisone twice a day after cleaning of penis with lukewarm water for four to six weeks. Gentle retraction of foreskin 10-20 times is also advised and a weekly follow-up for eight weeks was made. The local side effect of Hydrocortisone cream, such as striae, pigmentation, telangiectasia and hypertrichosis was informed to the parents.

Data collection and statistical analysis was done using SPSS 22.0. The different study variables were analyzed using descriptive statistics.

\section{Results}

Forty-nine patients, age range from 1 year to 8 years $(3.28+1.60)$ were evaluated retrospectively. All the patients were diagnosed as physiological phimosis, Kikiros and Woodward retractability grade of 3, 4 and 5 with associated symptoms, such as difficulty in passing urine $(n=16,32.65 \%)$, ballooning of prepuce $(n=29$, $59.18 \%)$ and retained smegma $(\mathrm{n}=4,8.16 \%)$. (Table 1 and Table 2) Out of $49(100 \%)$ patients $40(81.63 \%)$ achieved complete response to steroid.

Table 1. Patients demographic features and outcomes

\begin{tabular}{|c|c|}
\hline $\mathrm{n}$ & $49(100 \%)$ \\
\hline Age in year $($ mean \pm SD) & $3.28+1.60$ \\
\hline $\begin{array}{l}\text { Symptoms: } \\
\text { difficulty in passing urine } \\
\text { ballooning of prepuce } \\
\text { retained smegma }\end{array}$ & $\begin{array}{l}n=16(32.65 \%) \\
n=29(59.18 \%) \\
n=4(8.16 \%)\end{array}$ \\
\hline $\begin{array}{l}\text { Outcome: } \\
\qquad 40(81.63 \%)\end{array}$ & $\begin{array}{l}\text { Kikiros and } \\
\text { Woodward } \\
\text { retractability grade: } \\
\text { grade } 0\end{array}$ \\
\hline $2(4.08 \%)$ & grade 1 \\
\hline $7(14.28 \%)$ & $\begin{array}{l}\text { grade } 4 \& 5 \text {; } \\
\text { underwent } \\
\text { circumcision. }\end{array}$ \\
\hline
\end{tabular}

In this study complete response is define as complete
Medical Journal of Pokhara Academy of Health Sciences Vol. 3 Issue 1 retraction of foreskin without band formation, which is Kikiros and Woodward retractability grade 0. 2(4.08\%) patients showed satisfactory response (symptom free) which is Kikiros and Woodward retractability grade 1. The parents of the patients were pleased with the results and refused for further procedure. Whereas $7(14.28 \%)$ patients showed no any response after six weeks course of treatment and underwent circumcision.

Table 2. Kikiros and Woodward retractability grading of the foreskin(10)

\begin{tabular}{|c|c|}
\hline Grade & Description \\
\hline 0 & $\begin{array}{l}\text { Full retraction, not tight behind glans, or } \\
\text { easy retraction limited only by congenital } \\
\text { adhesions to the glans }\end{array}$ \\
\hline 1 & $\begin{array}{l}\text { Full retraction of foreskin, tight behind the } \\
\text { glans }\end{array}$ \\
\hline 2 & $\begin{array}{l}\text { Partial exposure of glans, prepuce (not } \\
\text { congenital adhesions) limiting factor }\end{array}$ \\
\hline 3 & Partial retraction, meatus just visible \\
\hline 4 & $\begin{array}{l}\text { Slight retraction, but some distance } \\
\text { between tip and glans, i.e., neither meatus } \\
\text { nor glans can be exposed }\end{array}$ \\
\hline 5 & Absolutely no retraction \\
\hline
\end{tabular}

\section{Discusion}

The diagnosis of phimosis is made clinically and no laboratory investigation is required. ${ }^{3}$ The attending surgeon should be able to differentiate physiological phimosis from pathological. The choice of the treatment for physiological phimosis has become controversial. In the past circumcision was the choice of treatment. But due to its surgical and anesthetic complication and financial burden various approaches such as stretching of prepuce, prepuce-plasty, steroid cream and ointment has been reported. ${ }^{3,4}$ In this study $1 \%$ hydrocortisone is used and the success rate is $81.63 \%$. Dewan et al. has reported effectiveness of $65 \%$ with $1 \%$ hydrocortisone cream. ${ }^{4}$ Recent articles have shown excellent outcome of topical steroid ranging $65 \%$ to $90 \%{ }^{4,5,6,7}$ The initial medical intervention has shown to reduce financial 
burden by $27.3 \%$ in compare to primary circumcision and complication is negligible. ${ }^{7,8}$ In the present days circumcision is reserved for pathological phimosis; balanoposthitis, scarred foreskin, Balanitis Xerotica Obliterans and medically failed physiological phimosis. ${ }^{9}$

The mechanism of topical steroid in phimosis is multifactorial. It is reported to be acted by two mechanisms, anti-inflammatory action and immunosuppressive effects ${ }^{7,10,11,12}$; 1.Through the stimulation of lipocortin production that inhibits phospholipase A2, thus reducing the production of arachidonic acid, precursor of prostaglandins and leukotrienes, mediators of skin inflammation. Corticosteroids are known to reduce early manifestations of inflammation (edema, fibrin deposition, capillary dilatation, migration of leucocytes and phagocyte activity), and late manifestations (proliferation of capillaries and fibroblasts, depletion of collagen and cicatrisation). 2.By inhibiting collagen synthesis by fibroblasts and its anti-proliferative effects on the epidermis, corticosteroids produce skin thinning and increase skin elasticity. ${ }^{11.12}$

A variable in the efficacy of topical corticosteroid is noted in various reported articles.

In this study the efficacy was $81.63 \% .4 .08 \%$ achieved Kikiros and Woodward retractability grade 1. In continuation of the treatment another cycle of topical application was advised. But the patient parents were so pleased with the results and refused for further treatment. All the patients were observed weekly for eight weeks and monthly afterward. $14.28 \%$ (7 patients) showed no response to the treatment and underwent circumcision.

However, parents education and understanding towards congenital phimosis and the time of natural resolution plays an important role in the treatment process. Along with hygiene maintenance, cleaning with lukewarm water before application of topical steroid and gentle retraction of foreskin routinely during bathing or after application of ointment results foreskin retractile over time. Parents are well explained about the application and complications of the steroid. Side effects were rare to mild and no significant effect were reported. ${ }^{13}$ All care providers should be aware of the consequences and should not attempt forcible retraction of foreskin to clean underneath.

\section{CONCLUSION}

The attending surgeon should be able to differentiate physiological phimosis from pathological. Patient caretaker and parents should be made aware of the treatment and technique. This study demonstrates the use of topical hydrocortisone is safe, simple and cost effective. Medical treatment has proven promising results and it could be the initial choice of treatment in physiological phimosis.

\section{References}

1. Shahid SK. Phimosis in Children. ISRN Urology.2012; 2012:707329.

2. Ko MC, Lui CK, Lee WK, Jeng HS, Chiang HS, Li CY. Age-specific prevalence rates of phimosis and circumcision in Taiwanese boys. J Formos Med Assoc. 2007;106(4):302-307.

3. Nascimento FJ, Pereira RF, Silva JL, Tavares A, Pompeo AC. Topical Betamethasone and Hyaluronidase in the Treatment of Phimosis in Boys: a Double-Blind, Randomized,Placebo controlled Trial. Int Braz J Urol. 2011 MayJun;37(3):314-319.

4. P. A. Dewan, H. C. Tieu, and B. S. Chieng, "Phimosis: is circumcision necessary?" Journal of Paediatrics and Child Health.1996;32(4):285-289.

5. Ashfield JE, Nickel KR, Siemens DR, 
Original Article

MacNeily AE, Nickel JC. Treatment of

phimosis with topical steroids in 194 children.

JUrol. 2003;169:1106-8.

6. Kuehhas FE, Miernik A, Sevcenco S, Tosev

G, Weibl P, Schoenthaler M, et al. Predictive power of objectivation of phimosis grade on outcomes of topical $0.1 \%$ betamethasone treatment of phimosis. Urology. 2012;80:4126.

7. Moreno G, Corbalan J, Penaloza B, Pantoja T. Topical corticosteroids for treating phimosis in boys (Review).Cochrane Database of Systematic Reviews. 2014; Issue 9. Art. No.: CD008973.

8. Nobre YD, freitas RG, Felizardo MJ, Ortiz $\mathrm{V}$, et al. to cric or not to cric: clinical and pharmoeconomic outcomes of a prospective trial of topical steroid versus primary circumsion. Int Braz J Urol. 2010;36(1):75-85

9. McGregor T, Pike J, Leonard M. Pathologic and physiologic phimosis Approach to the phimotic foreskin. Can Fam Physician. 2007;53:445-448.

10. Kikiros CS, Beasley SW, Woodward AA. The response of phimosis to local steroid application. Pediatr Surg Int. 1993;8:329-332.

11. Marques TC, Sampaio FJ, Favorito LA. Treatment of phimosis with topical steroids and foreskin anatomy. International Brazilian
Medical Journal of Pokhara Academy of Health Sciences Vol. 3 Issue 1 Journal of Urology. 2005;31(4):370-4.

MEDLINE: 16137407

12. Zampieri N, Corroppolo M, Zuin V, Bianchi S, Camoglio FS. Phimosis and topical steroids: new clinical findings. Pediatric Surgery International. 2007;23(4):331-5. MEDLINE: 17308904

13. J. M. Elmore, L. A. Baker, W. T. Snodgrass, and P. Dewan, "Topical steroid therapy as an alternative to circumcision for phimosis in boys younger than 3 years," Journal of Urology. 2002;168(4):1746-1747. 